\title{
LABORATORIO
}

\section{Estandarización del inmunoensayo ELISA para la detección de IgG anti-Toxoplasma gondii en ratón}

\author{
NÉSTOR IVÁN CARDONA*, FABIANA LORA* y JORGE ENRIQUE GOMEZ*
}

\section{STANDARIZATION OF AN ENZYME-LINKED IMMUNOSORBENT ASSAY (ELISA) FOR DETECCTION OF SPECIFIC ANTI- Toxoplasma gondii IgG IN MICE}

We describe a standardization of an enzyme-linked immunosorbent assay (ELISA) for detection of specific anti-Toxoplasma gondii IgG in mice. This assay is important as a tool for strains characterization in $\mathbf{T}$. gondii and for diagnosis of human toxoplasmosis. The technique was standardized by testing different conditions (different coating reagents and different amounts of antigen). No significant difference was observed between coating reagents; therefore buffer coating with bovine albumin 1\% was chosen. The best amount of antigen was $20 \mu \mathrm{g} / \mathrm{ml}$ at a 1:1000 dilution of the secondary antibody. The cut-off was the average value of all negative serum +2 deviation standard $(0,135)$. Negative serum values were below of cut-off at $410 \mathrm{~nm}$. We do not found differences in detection among strains of $\boldsymbol{T}$. gondii. These results show that ELISA is highly sensitive and specific and is useful to improve efficiency in procedures that involve animals in the laboratory.

Key words: Toxoplasma gondii, ELISA, IgG.

\section{INTRODUCCIÓN}

La toxoplasmosis es una infección producida por un parásito protozoario intracelular obligado denominado Toxoplasma gondii, el cual infecta al hombre y a la mayoría de animales de sangre caliente, tanto domésticos como salvajes ${ }^{1}$. Los estudios seroepidemiológicos hasta el presente demuestran que aproximadamente la mitad de la población mundial en algún momento de su vida ha sido infectada por este protozoo ${ }^{2}$.

En humanos sanos la infección por Toxoplasma generalmente no produce sinto- matología e induce una inmunidad protectora perdurable contra la reinfección; sin embargo, puede ser una seria enfermedad cuando se adquiere transplacentariamente (toxoplasmosis congénita) o en pacientes inmunocomprometidos, especialmente aquellos que padecen $\mathrm{VIH}^{3}$.

Es de gran interés el análisis de la cinética y el perfil isotópico de la respuesta inmune hacia la infección experimental con $T$. gondii, ya sea para la optimización del inmunodiagnóstico o para el entendimiento de los mecanismos de protección. Estudios previos han establecido que la importancia de los anticuerpos en la mediación

\footnotetext{
Grupo de Parasitología Molecular -GEPAMOL- Centro de Investigaciones Biomédicas, Facultad de Ciencias de la Salud, Universidad del Quindío.

Correspondencia: Jorge E. Gómez Marín, Grupo Estudio en Parasitología Molecular (GEPAMOL), Centro de Investigaciones Biomedicas Universidad del Quindío, Armenia (Q) Tel/Fax: +57-67-460168 e-mail: gepamo2@uniquindio.edu.co
} 
de la respuesta inmune hacia T.gondii depende del modelo de estudio. En el laboratorio son utilizados ratones y ratas debido a que su resistencia natural a la infección por T.gondii es similar a aquella en humanos sanos ${ }^{4}$. El modelo animal para estudiar la infección producida por las diferentes cepas de $T$. gondii es el ratón, pero muchas veces estos no enferman debido a causas como su estado inmune. Además las cepas provenientes de muestras humanas tienen la tendencia de volverse crónicas en el ratón y no dan síntomas en el animal ${ }^{4}$. Este proceso de infección por medio de inoculación de ratones requiere ser comprobado mediante pruebas serológicas. Es por ello que se ve la necesidad de estandarizar un ELISA ya esta es una prueba inmunológica de alta sensibilidad lo que permite determinar si el proceso de infección fue exitoso o no. En Colombia no se ha reportado el uso de ELISA para prueba de IgG anti-Toxoplasma en ratón.

Esta técnica seria de inmenso valor para ser utilizada en laboratorios de referencia que requieran analizar muestras tales como líquidos corporales, placenta o biopsia de tejidos. La estandarización de esta técnica permitirá contar con una nueva herramienta para el diagnostico y la investigación en toxoplasmosis.

\section{MATERIAL Y MÉTODOS}

Ratones: Se utilizaron ratones blancos suizos (hembras) de la cepa ICR proporcionados por el bioterio de la Universidad Nacional de Colombia con 4-5 semanas de nacidos y con un peso aproximado de 20 gramos.

Parásitos: Se inocularon ratones vía intraperitoneal con taquizoítos de $T$. gondii cepa RH (donada por la Dra. Sánchez, Universidad Los Andes, Bogotá) a una dosis de 100.000 taquizoítos vivos resuspendidos en solución salina estéril y antibiótico. Los taquizoítos se recuperaron 3-4 días después de la cavidad peritoneal por medio de instilación de de solución salina al $0,8 \%$ estéril, conteniendo antibiótico (penicilina 1.000 unidades/ml y gentamicina 10 $\mu \mathrm{g} / \mathrm{ml})$. Se hicieron observaciones al microscopio óptico y tinción con azul tripan para verificar la presencia y viabilidad de los taquizoítos.

Muestras: Las muestras de suero se obtuvieron a partir de ratones antes de ser inoculados (controles negativos) y luego de 1 mes de haber sido inoculados con taquizoítos de $T$. gondii (controles positivos) de la cepa RH y vía oral con cepa PRU (donada por la Dra. Dardé, Limoges, Francia) a una dosis de $100 \mu \mathrm{L}$ de tejido cerebral homogenizado. La extracción de sangre se hizo practicando un corte apical en la cola del ratón. La sangre se recogió en viales de $1 \mathrm{ml}$ y se centrifugó durante 10 minutos a 3.000 rpm para la obtención del suero.

Antígeno total soluble de T. gondii: Una vez obtenidos los taquizoítos en la cavidad peritoneal de los ratones, se lavaron por centrifugación por duplicado a $2.500 \mathrm{rpm}$ por 15 minutos con solución salina $0,85 \%$ con la concentración de antibiótico descrita (penicilina 1.000 unidades/ $\mathrm{ml}$ y gentamicina $10 \mu \mathrm{g} / \mathrm{ml})$. El sedimento se resuspendió en $5 \mathrm{ml}$ de solución salina $0,85 \%$ estéril y se filtro a través de una membrana estéril de policarbonato con una porosidad de 3 $\mu \mathrm{m}$, y se verificó por microscopía que el preparado estuviera libre de células de ratón. El filtrado se centrifugó a $3.500 \mathrm{rpm}$ por 5 minutos, el sedimento obtenido se resuspendió en $1,0 \mathrm{ml}$ de solución salina estéril. A continuación se procedió a realizar rompimiento de membrana del parásito mediante 5 ciclos de congelación/ descongelación y 5 ciclos de sonicación a 18.000 $\mathrm{Hz}$. Se verificó por medio de microscopia la lisis del parásito. Se centrifugó a $1.000 \mathrm{rpm}$ por 60 minutos, se recuperó el sobrenadante al cual se le determinó concentración de proteínas mediante la técnica de Lowry. A este producto se le adicionó una mezcla de inhibidores de proteasa (PMSF $1 \mathrm{mM}$ EDTA $0,5 \mathrm{mM}$ Pepstatina A 1 $\mathrm{mM}$ ) y se almacenó a $-70^{\circ} \mathrm{C}$ hasta su utilización ${ }^{5}$.

Ensayo Inmunoenzimatico (ELISA): Se realizó un ensayo imnunoenzimatico en fase solida fijando $100 \mu \mathrm{L}$ de antígeno total soluble de Toxoplasma en una placa $\operatorname{COSTA}^{\circledR}$ en concentraciones de $1,25 \mu \mathrm{g} / \mathrm{ml}, 2,5 \mu \mathrm{g} / \mathrm{ml}, 5 \mu \mathrm{g} /$ $\mathrm{ml}, 10 \mu \mathrm{g} / \mathrm{ml}, 20 \mu \mathrm{g} / \mathrm{ml}$ utilizando como diluyente tampón de recubrimiento $\left(1,5 \mathrm{~g} \mathrm{Na}_{2} \mathrm{CO}_{3} ; 2,93 \mathrm{~g}\right.$ $\mathrm{NaHCO} ; 0,2 \mathrm{~g} \mathrm{NaN}_{3}$ en 1 litro de agua destilada a pH 9,6). La placa se dejo fijando en cámara húmeda por 2 horas a temperatura ambiente $\mathrm{y}$ luego por 16 horas durante toda la noche a $4^{\circ} \mathrm{C}$. Se bloqueó con $350 \mu \mathrm{L}$ de tampón de recubrimiento-leche 5\%, PBS tween 20 0,05\%, tampón de recubrimiento-albúmina $1 \%$ y PBS por 30 minutos a temperatura ambiente. Se adicionó la muestra (sueros positivos y negativos) a razón de $100 \mu \mathrm{L}$ por pozo con dilución 1:100 y 
se incubó por una hora a $37^{\circ} \mathrm{C}$. Transcurrido el tiempo se adicionó $100 \mu \mathrm{L}$ del conjugado antimouse IgG (SIGMA, St. Louis, MO) con dilución 1:30.000 en PBS Tween 20 y se incubó en cámara húmeda a $37^{\circ} \mathrm{C}$ por 30 minutos, al cabo de los cuales se adicionó $100 \mu \mathrm{l}$ de sustrato para fosfatasa alcalina (SIGMA, St. Louis, MO) en cada pozo. Se incubó por 30 minutos y se adicionaron $100 \mu \mathrm{l}$ de $\mathrm{NaOH} 8 \mathrm{~N}$ como reacción de parada. Luego se procedió a leer a $410 \mathrm{~nm}$ en un lector de ELISA (Dynatech 5.000, USA). Los datos obtenidos en las pruebas ELISA fueron la densidad óptica (DO) para cada muestra de suero analizada. Se interpretaron los resultados de acuerdo a la DO. El punto de corte (cut-off) se calculó como el promedio de los sueros negativos \pm 2 desviaciones estándar.

Prueba de reacción cruzada: Se trabajó para el desarrollo de la prueba de reacción cruzada con sueros de ratones inmunizados con proteína de secreción-excreción de cisticerco de Taenia solium (donado por el Dr. Castaño, Universidad del Quindío) e infectados con Plasmodium berghei (donado por Dr. Herrera y Dr. Valderrama, Universidad del Valle) utilizando las mismas condiciones de estandarización antes mencionadas.

Para la obtención de sueros se inoculó un ratón intraperitonealmente con $100 \mu \mathrm{L}$ de sangre con $P$. berghei. A los 3 días de haber sido inoculado se realizó un examen de gota gruesa con el fin de verificar la presencia del parásito en sangre, y así sucesivamente hasta completar 1 mes.

Para cisticerco se inocularon ratones con una primera dosis de $500 \mu \mathrm{L}$ de Proteína SecreciónExcreción de cisticerco (PSE) $+500 \mu \mathrm{L}$ de adyuvante completo. La segunda dosis se realizó a los 10 días postinoculación (p.i) con $300 \mu \mathrm{L}$ de PSE $+300 \mu \mathrm{L}$ de adyuvante completo. La tercera dosis se realizó a los 20 días p.i con $150 \mu \mathrm{L}$ de PSE $+150 \mu \mathrm{L}$ de adyuvante incompleto. La cuarta dosis se realizó a los 30 días p.i con 100 $\mu \mathrm{L}$ de PSE $+100 \mu \mathrm{L}$ de adyuvante incompleto.

\section{RESULTADOS}

El punto de corte (cut-off) obtenido por el promedio de los sueros negativos \pm 2 desviaciones estándar fue 0,135 (Figura 1). Se consideraron como positivos aquellos sueros que presentaron valores de DO por encima del cut-

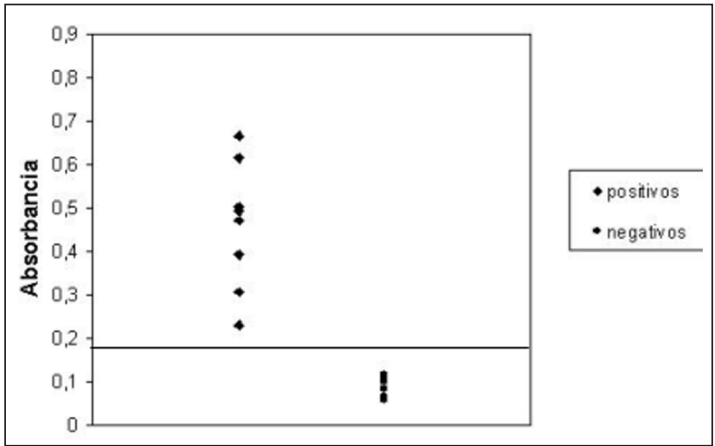

Figura 1. Dispersión de los valores de absorbancia entre sueros de ratones control y ratones inoculados con Toxoplasma.

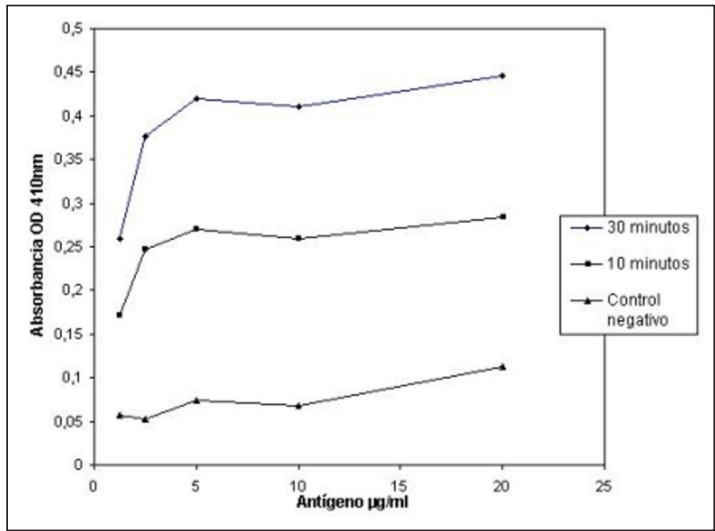

Figura 2. Concentración de antígeno con relación a la D.O.

off. Los sueros control negativos o verdaderos negativos son los sueros de ratón tomados preinoculación del Toxoplasma. Los sueros controles positivos o verdaderos positivos son los sueros de ratón tomados 4 semanas de haber sido inoculados con Toxoplasma.

A concentraciones de $1,25 \mu \mathrm{g} / \mathrm{ml}, 2,5 \mu \mathrm{g} / \mathrm{ml}$, $5 \mu \mathrm{g} / \mathrm{ml}$ no se encontraron variaciones significativas en la DO, mientras que a concentraciones de $10 \mu \mathrm{g} / \mathrm{ml}$ y $20 \mu \mathrm{g} / \mathrm{ml}$ los valores de DO fueron los mas altos (Figura 2).

Con relación al tiempo de revelado del anticuerpo secundario con el sustrato, se presentaron mayores valores de DO después de 30 minutos (Figura 2).

El agente bloqueador mas eficaz fue el tampón de recubrimiento con albúmina bovina al $1 \%$, este permitió los mayores valores de DO luego de 30 minutos de revelado con el sustrato (Figura 3 ). 


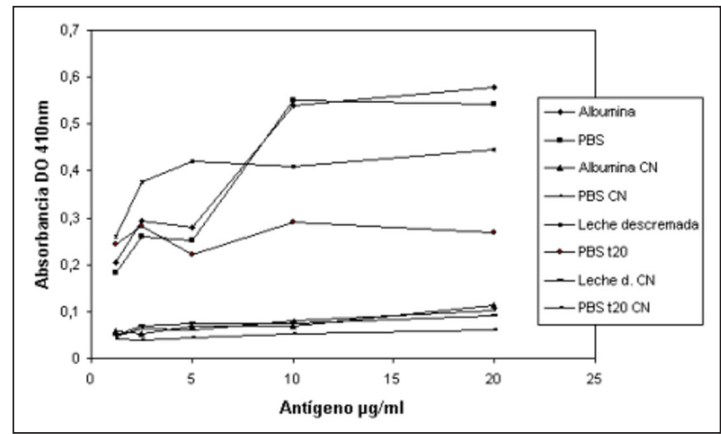

Figura 3. Comparación entre bloqueadores.

La reactividad de los sueros de ratones infectados con P. berghei (DO: $0,057 \pm 0,006$ ) e inmunizados con cisticerco de $T$. solium $(0,042$ $\pm 0,003)$ al antígeno de $T$. gondii a través de la prueba de ELISA indirecto estuvo por debajo del punto de corte para la correspondiente prueba (DO: 0,154). Se probaron todos los sueros por duplicado. El promedio de los resultados de densidad óptica para los sueros negativos fue de $0,078 \pm 0,034$. Se utilizó como control positivo el suero de un ratón infectado con cepa PRU de $T$. gondii cuyo promedio de densidad óptica fue de 0,176 .

\section{DISCUSIÓN}

El cultivo en ratón es un complemento necesario para el diagnostico de toxoplasmosis clínica tanto en forma congénita como en el inmunosuprimido ${ }^{6,7}$, a partir de muestras de líquido amniótico o líquido cefalorraquídeo. El PCR es más sensible que la inoculación en ratón, pero si el PCR es negativo se debería realizar esta, pues en ocasiones es la única prueba que da resultado positivo en un niño infectado 4 . Para esto es necesario utilizar una prueba serológica que testifique la infección en el ratón con el fin de optimizar los procedimientos de investigación en el laboratorio clínico. Se debe tener en cuenta que en ratones la aparición de anticuerpos detectables tiene lugar 4 semanas después de la inoculación ${ }^{4}$.

Los valores de absorbancia más altos se presentaron utilizando concentraciones de antígeno de $20 \mu \mathrm{g} / \mathrm{ml}$. Sin embargo, concentraciones menores permitieron diferenciar entre sueros positivos y negativos. Esto muestra que la técnica tiene buena sensibilidad aun con bajas concentraciones de antígeno. El antígeno utilizado para la prueba ELISA IgG fue de fácil ejecución $\mathrm{y}$ de buen rendimiento. El procedimiento de preparación de antígeno tratado por congelación y sonicación presentó resultados satisfactorios.

No hubo diferencia significativa entre agentes bloqueadores por lo que se decidió utilizar el tampón de recubrimiento con albúmina bovina al $1 \%$, este permitió los mayores valores de DO luego de 30 minutos de revelado con el sustrato. El inmunoensayo permitió una clara discriminación de sueros negativos y sueros positivos.

La técnica de ELISA tiene una gran ventaja por su simplicidad, sensibilidad y especificidad. La estandarización de la prueba ELISA IgG para diagnóstico serológico de toxoplasmosis en ratón fue realizada con la tentativa de obtener una prueba altamente sensible y específica de aplicación práctica para muchos laboratorios. Se espera que contribuya a determinar si el proceso de inoculación fue exitoso o no y si hubo seroconversión a partir cepas potencialmente crónicas, lo cual es un paso importante para lograr aislamientos exitosos de las mismas en nuestro medio ya sea a partir de muestras humanas o animales.

\section{RESUMEN}

Se describe la estandarización de un inmunoensayo (ELISA) para la detección de IgG contra Toxoplasma gondii en ratones. Este ensayo tiene interés como herramienta en el estudio de cepas y en el diagnostico de la toxoplasmosis en muestras de origen humano. Se determinaron las mejores condiciones para la realización de la prueba (diferentes agentes bloqueadores y diferentes concentraciones de antígeno). No hubo diferencia significativa en cuanto a la función de los agentes bloqueadores, por lo que se decidió trabajar con tampón de recubrimiento con albúmina bovina al $1 \%$. El valor óptimo de concentración de antígeno fue $20 \mu \mathrm{g} / \mathrm{ml}$, para el conjugado la dilución óptima fue de 1:1.000. El punto de corte fue estimado como el promedio de los sueros negativos más dos desviaciones estándar $(0,135)$. Todos los sueros negativos presentaron valores de absorbancia a $410 \mathrm{~nm}$ menores al punto de corte. No se encontraron diferencias para la detección entre cepas de $T$. gondii. Los resultados muestran que la prueba ELISA es altamente sensible y 
especifica y es de gran utilidad para la optimización de los procedimientos que se realizan en animales de laboratorio.

\section{REFERENCIAS}

1.- NICOLE C, MANCEAUX L. Sur un protozoaire nouveau de Gondi, Toxoplasma. Archives Institut Pasteur (Tunis) 1909; 2: 97-103.

2.- SHERRIS J C. Esporozoos. Microbiología Médica. Editorial Doyma. España. 1993 Cap. 52: 783-815.

3.- GODARD I, DARCY F, DESLEE A, et al. Isotypic Profiles of Antibody Responses to Toxoplasma gondil Infection in Rats and Mice: Kinetic Study and Characterization of Target Antigens of Immunoglobulin A Antibodies. Infection and Immunity 1990; 2446-51.
4.- LÓPEZ M C, CORREDOR A, REYES P, et al. Estandarización de una prueba de inmunoflorescencia indirecta para IgG anti-Toxoplasma en ratón. Biomédica 2001; 21: 79-82.

5.- CASTAÑO OSORIO J C, MARTÍNEZ FUNDORA A $\mathrm{R}$, SÁNCHEZ R M, et al. Producción de anticuerpos monoclonales contra las proteínas mayoritarias de la membrana p30 (SAG1) y p22 (SAG2) de Toxoplasma gondii. Revista de Investigaciones Universidad del Quindío 2003; 4: 97-106.

6.- FOULON W, PINON J M, STRAY-PEDERSEN B, et al. Prenatal diagnosis of congenital toxoplasmosis: a multicenter evaluation of different diagnosis parameters. Am J Obstet Gynecol 1999; 181: 843 7.

7.- DIEGO J A, VASQUEZ J J, PENIN P. Use of murine subinoculation for the diagnosis an isolation of toxoplasmosis in HIV-infected patines with persistet lymphadenopathy. Ann Trop Med 1993; 87: 179-84.

\section{Nueva fecha de cierre: 15 de agosto de 2005}

\section{Congreso Latinoamericano de Parasitología IV Congreso Argentino de Parasitología XXIX Jornadas Internacionales de Hidatidología}

23 a 26 de noviembre, 2005

Organizan: Federación Latinoamericana de Parasitología. Sociedad Argentina de Parasitología Asociación Internacional de Hidatología

Hotel Costa Galana

Boulevard Marítimo P. P. Ramos 5725

Mar del Plata, Argentina 